\author{
산란계 사료에 Glutinicus 첨가가 산란 생산성, \\ 난각 및 난황 색도에 미치는 영향 \\ 정병윤 · 임희석 · 백인기 \\ 중앙대학교 동물자원과학과
}

\title{
The Effects of the Glutinicus Supplementation on Performance, Eggshell and Egg Yolk Color of Layers
}

\author{
B. Y. Jung, H. S. Lim and I. K. Paik \\ Department of Animal Science and Technology, Chung-Ang University
}

\begin{abstract}
An experiment was conducted to determine the effects of dietary supplementation of the yeast Rhodotorula glutinis(Glutinicus) on the performance and egg quality of layers. A total of 360 ISA Brown layers at 72 weeks old were assigned to one of the following 6 diets: control, $25 \mathrm{ppm} \beta$-carotene, $0.5 \%, 1 \%, 2 \%$ and $4 \%$ Glutinicus supplemented diets. Each treatment was replicated three times with 20 birds housed in 2 bird cage units.

Glutinicus supplementation at the level of $0.5 \%$ significantly $(\mathrm{p}<0.05)$ improved egg production and FCR. Soft and broken egg production rate decreased as the level of Glutinicus supplementation increased. Eggshell strength was highest in $4 \%$ Glutinicus supplementation. Egg yolk color increased linearly as the level of Glutinicus supplementation increased up to $2 \%$ of the diet. It was concluded that Glutinicus supplementation at the level of $0.5 \%$ can be recommended for the improvement of egg production while $2.0 \%$ can be recommended for egg yolk pigmentation.
\end{abstract}

(Key words : Glutinicus, Egg production, Soft and broken egg, Egg yolk color)

$$
\mathrm{I} \text { 서 론 }
$$

Carotenoids의 미생물 원료로서 Dunaliella spp. 와 같은 해조류와 Phafia rhodozyma와 Rhodotorula glutinis(Glutinicus)와 같은 효모제가 상업적으로 관심을 끌고 있다(Nelis와 DeLeenheer, 1991; Eugiena 등, 1997). Rhodotorula glutinis는 carotenoid, torularhodin, torulene과 $\beta$-carotene 을 다 양한 비율로 생산하지만(Perrier 등, 1995), 야생종 인 Rhodotorula glutinis에서 $\beta$-carotene의 함유량 은 비교적 낮다(Bindu 등, 1998). Carotenoids는 일반적으로 지용성이며 공액 이중결합의 수
가 많을수록 황색에서 적색으로 이행하는 것으로 알려져 있으며 불포화도가 매우 높기 때문에 열, 산, 빛, 금속이온, 과산화물, 화학약 품, peroxidase 등에 쉅게 산화되어 파괴되는 특 징이 있다. 이러한 carotenoids는 발색원인이 되 는 conjugated double bonds의 구조를 가지고 있 어 유해한 것으로 알려진 free radical을 포집하 거나 항산화 기능을 나타낸다(Tee, 1992). 특히 $\beta$-carotene 및 astaxanthin 등은 암 발생을 억제하 고 강력한 항산화성을 나타낼 뿐만 아니라 vita$\min \mathrm{A}$ 의 전구체, 동물의 번식 촉진, 질병 발생 억제, 어류의 색상 개선 및 식물의 광합성을 도

Corresponding author : I. K. Paik. Dept. of Animal Science, Chung-Ang University, Ansung-si, Kyonggi-Do, Korea 456-756. Tel : (031) 670-3028, Fax : (031) 676-2196, E-mail : ikpaik@cau.ac.kr 
와 주는 특성이 있다고 하였다(Bauerfeind, 1981; Pierre, 1997; Kearsley, 1981; 홍, 1996). 또한 carotenoids는 난황과 닭 피부의 착색에 관여하 지만(Marusich와 Bauernfeind, 1981) 닭은 체내에 서 carotenoid를 합성할 수 없기 때문에 사료에 서 흡수하여야 한다(Dua 등, 1967; Twining 등, 1971). Cole과 Haresign(1981), Miki(1991)는 조류 에서 carotenoid(주로 xanthophylls)는 위에서 흡 수되어 피부, 깃털, 지방조직, 난황 등 여러 조 직에 상당량 축적된다고 보고하였으며, 이때 흡수된 carotenoid는 피부에서는 주로 esterified carotenoids의 형태로 존재하지만, 난황에는 free carotenoids로 존재한다고 하였다.

Rhodotorula glutinis와 같은 효모제는 장내 미 생물에 대해 농축된 영양소의 공급원으로 작용 하며(Cartwright 등, 1986), 산소와 강력한 친화 력을 가지고 있기 때문에 장내의 산소를 제거 하여 혐기상태를 만듦으로써 혐기적 유익균의 증식을 도모하여 간접적으로 증체량, 사료효율 과 산란율을 개선시킨다(Ringrose, 1949; Rose, 1987; Pagan, 1989; Newbold 등, 1990; Shin 등, 1990 ; 고 와 황, 1999 ; 백, 1989; 이 등, 1995).

본 실험의 목적은 산란계 사료에 carotenoid 함량이 $275 \mu \mathrm{g} / \mathrm{g}$ 이며, 조성이 torularhodin $61.7 \%$, $\beta$-carotene $28.8 \%$, torulene $9.6 \%$ (박과 김, 2002) 인 Glutinicus의 첨가가 난황 색도에 미치는 영 향과 산란 생산성 및 난각의 품질에 미치는 영 향을 검정하기 위해 실시하였다.

\section{재료 및 방법}

\section{1. 시험 설계}

72주령된 산란계(ISA-Brown) 360수를 대조구 를 포함하여 총 6 개의 처리군으로 구성하여 처 리당 3 반복, 반복당 10 케이지, 케이지당 2수씩 (처리당 60수씩 총 360수) 수용하여 난괴법으로 배치하였다.

시험사료는 시중에서 판매되는 CP $18.5 \%$, $\mathrm{ME} 2,800 \mathrm{kcal} / \mathrm{kg}$, Ca $3.9 \%$ 인 산란중기사료에 $1 \%$ 의 토코페롤을 첨가하여 대조구로 사용하였 으며 배합비 및 영양소 함량은 Table 1 과 같다.
처리 내용은 Table 2에서 보는 바와 같이 처리 에 따른 $\beta$-carotene과 (주)유진사이언스에서 생 산된 Rhodotorula glutinis(Glutinicus)를 농도별로 첨가하여 시험 하였다. 첨가한 Glutinicus의 성 분과 carotenoid 함량 및 조성을 분석한 결과는 Table 3과 같으며, 사양 관리는 시험사료를 4월 중순부터 6주간 급여하고 시험기간 동안 물과 사료는 자유 섭취하게 하였고 정상적인 점등관 리(16시간)를 실시하였다.

Table 1. Formula and composition of control diet

\begin{tabular}{|c|c|c|c|}
\hline \multirow{2}{*}{$\begin{array}{l}\text { Ingredient } \\
\text { Corn }\end{array}$} & \multirow{2}{*}{$\begin{array}{r}\begin{array}{r}\text { Percent } \\
\text { of Mix }\end{array} \\
52.10\end{array}$} & \multicolumn{2}{|c|}{ Calculated composition } \\
\hline & & $\mathrm{ME}, \mathrm{kcal} / \mathrm{kg}$ & 2,800 \\
\hline Soybean meal & 25.07 & Calcium, \% & 3.9 \\
\hline Rice bran & 0.99 & Total P, \% & 0.5 \\
\hline Wheat bran & 2.97 & Non-Phytate P, \% & 0.4 \\
\hline Ca-phosphate & 0.79 & Crude protein, \% & 18.5 \\
\hline Limestone & 9.21 & Lysine, \% & 0.8 \\
\hline Fat $^{1)}$ & 3.73 & Methionine, \% & 0.4 \\
\hline Salt & 0.25 & Meth.+Cys., \% & 0.7 \\
\hline Corn gluten & 2.73 & Choline, mg/kg & 1,250 \\
\hline Additives & 0.14 & Crude fat, \% & 5.3 \\
\hline Meat\&bone meal & 0.99 & Crude fiber, \% & 3.1 \\
\hline Vitamin premix ${ }^{2)}$ & 0.12 & Crude ash, \% & 13.2 \\
\hline Mineral premix ${ }^{3}$ & 0.12 & & \\
\hline phytase $^{4)}$ & 0.03 & & \\
\hline Choline & 0.06 & & \\
\hline Methionine & 0.11 & & \\
\hline Total & 100 & & \\
\hline
\end{tabular}

${ }^{1)}$ Mixture of tallow and soybean oil( $\left.2.73: 1\right)$.

${ }^{2)}$ Contains per kg: vitamin $\mathrm{A}, 10,000,000 \mathrm{IU}$; vitamin $\mathrm{D}_{3}, 2,500,000 \mathrm{IU}$; vitamin $\mathrm{E}, 15,000 \mathrm{IU}$; vitamin $\mathrm{K}_{3}$, 2,000 mg; vitamin $B_{1}, 1,500 I U$; vitamin $B_{2}, 4,000$ mg; vitamin $\mathrm{B}_{6}, 3,000 \mathrm{mg}$; vitamin $\mathrm{B}_{12}, 3,000 \mu \mathrm{g}$; Pantothic Acid, 8,000 mg; nicin, 25,000 mg; folic acid, $500 \mathrm{mg}$.

${ }^{3)}$ Provides per kg diet: Zn, $52.5 \mathrm{mg}$; Mn, $52.5 \mathrm{mg}$; Fe, $52.5 \mathrm{mg}$; Cu, $5.25 \mathrm{mg} ; \mathrm{I}, 1.155 \mathrm{mg}$; Co, $0.315 \mathrm{mg}$; Se, $0.315 \mathrm{mg}$.

${ }^{4)}$ Phytase: provided by BASF Korea Ltd. 
Table 2. Treatment of experimental diets

\begin{tabular}{ccc}
\hline Treatment & \multicolumn{1}{c}{ Content } \\
\hline \hline 1 & Control \\
2 & Control + $\beta$-carotene & $25 \mathrm{ppm}$ \\
3 & Control + Glutinicus & $0.5 \%$ \\
4 & Control + Glutinicus & $1 \%$ \\
5 & Control + Glutinicus & $2 \%$ \\
6 & Control + Glutinicus & $4 \%$ \\
\hline
\end{tabular}

Table 3. Composition of Glutinicus

\begin{tabular}{|c|c|c|c|}
\hline \multirow{2}{*}{$\begin{array}{l}\text { Nutrient content } \\
\text { of Glutinicus, \% } \\
\text { Dry matter }\end{array}$} & \multicolumn{3}{|c|}{$\begin{array}{l}\text { Amino acid, \% of } \\
\text { Air dry matter }\end{array}$} \\
\hline & 99.70 & Aspartic acid & 2.87 \\
\hline Moisture & 0.27 & Threonine & 1.39 \\
\hline Crude ash & 5.78 & Serine & 1.37 \\
\hline Crude protein & 29.40 & Glutamic acid & 3.43 \\
\hline Crude fat & 7.97 & Proline & 1.19 \\
\hline Crude fiber & 0.07 & Glycine & 1.88 \\
\hline NFE & 52.63 & Alanine & 2.32 \\
\hline Mineral, mg/kg & & & \\
\hline Iron & 42 & & \\
\hline Phosphorus & 176 & Isoleucine & 1.20 \\
\hline Calcium & 967 & Leucine & 2.14 \\
\hline Potassium & 3,521 & Tyrosine & 0.90 \\
\hline Carotenoids $^{1)}, \mu \mathrm{g} / \mathrm{g}$ & 275 & Phenylalanine & 1.08 \\
\hline Torularhodin, \% & 61.7 & Histidine & 3.08 \\
\hline$\beta$-carotene, \% & 28.8 & Lysine & 0.61 \\
\hline Torulene, \% & 9.6 & Arginine & 2.09 \\
\hline
\end{tabular}

${ }^{1)}$ Assayed by Park and Kim(2002).

\section{2. 조사 항목}

산란율(hen-day, hen-housed), 평균 난중, 연파 란율을 매일 측정하여 주 별 평균을 계산하였 고, 사료 섭취량은 주 1 회 조사하여 사료 요구 율을 산출하였다.

난각 품질 검사는 주 1 회씩 총 6 회에 걸쳐 주중 하루에 생산된 총 계란 중 연파란을 제외 한 모든 계란을 취하여 실시하였다. 난각강도는 Texture Test Systems(T2100C, Food Technology Co., USA)를 이용해 측정하였고 난각색도와 색
상은 Eggshell Color Fan((주)삼양사배합사료)과 Color Difference Meter(Color Quest ${ }^{\circledR}$, Henterlab, USA)를 이용해 측정하였다.

난황 색도는 주 1 회씩 총 6 회에 걸쳐 주중 하루에 생산된 총 계란을 취하여 Egg yolk Color Fan(Roche)을 이용하여 측정하였다.

\section{3. 화학분석 및 통계 처리}

Rhodotorula glutinis(Glutinicus)의 일반 조성분 및 미네랄 함량 분석은 $\mathrm{AOAC(1990)} \mathrm{방법에} \mathrm{준}$ 하여 실시하였으며, 아미노산 함량 분석은 S7130 amino acid reagent organizer ${ }^{\mathbb{R}}$ (Syknm, Germany) 를 이용하여 실시 하였다. 시험에서 얻어진 자 료의 통계처리를 위하여 각 반복당 주당 평균 생산성을 이용하여 SAS(1985)의 GLM(General Linear Model) Procedure를 이용하여 분석하였다. 각 처리의 평균간의 유의차는 Duncan's new multiple range test에 의하여 $\mathrm{P}<0.05$ 에서 검정하였다.

\section{III 결과 및 고찰}

1. 일계 산란율, 산란지수, 사료 섭취량, 사 료 요구율

Table 4에서 보는 바와 같이, 일계 산란율과 산란지수는 6주 평균에서 대조구 보다 처리구 들이 높았는데 이는 유와 백(1990), Gerendia 등 (1992) 및 $\operatorname{Lim}(1992)$ 이 보고한 산란율 개선효과 와 유사하였다. 특히 Glutinicus $0.5 \%$ 첨가구에 서 유의하게 $(\mathrm{P}<0.05)$ 높았고 그 이상의 첨가구 에서는 추가적인 개선효과가 없었다. 이는 효 모의 일종인 Glutinicus가 SCP(single cell protein) 중의 하나로서 아미노산의 조성이 양호하 고 효소, 항생물질, 비타민, chelate 광물질 등의 공급원으로 작용하지만 $\mathrm{SCP}$ 는 세포막이 두껍 고, RNA가 다량 함유되어 있어서 과다 섭취 시 영양소 흡수율을 감소시키기 때문일 것이다 (Esmail, 2003). 사료 섭취량은 6주 평균에서 $\beta$ carotene 첨가구가 가장 낮았으며 대조구와 다 른 처리구들 간에는 유의적 차이가 없었다. 사 
Table 4. Laying performance, eggshell quality and egg yolk color during the 6 wk experiment

\begin{tabular}{|c|c|c|c|c|c|c|c|}
\hline \multirow{2}{*}{ Item } & \multicolumn{6}{|c|}{ Treatment $^{1)}$} & \multirow{2}{*}{ SEM } \\
\hline & $\mathrm{T} 1$ & $\mathrm{~T} 2$ & T3 & $\mathrm{T} 4$ & T5 & T6 & \\
\hline \multicolumn{8}{|l|}{ Perfomance } \\
\hline $\begin{array}{l}\text { Hen-day egg } \\
\text { prduction, \% }\end{array}$ & $71.17^{\mathrm{b}}$ & $75.74^{\mathrm{a}}$ & $76.43^{\mathrm{a}}$ & $73.93^{\mathrm{ab}}$ & $74.05^{\mathrm{ab}}$ & $74.94^{\mathrm{ab}}$ & 1.276 \\
\hline $\begin{array}{l}\text { Hen-housed egg } \\
\text { production, \% }\end{array}$ & $71.17^{b}$ & $74.74^{\mathrm{ab}}$ & $76.43^{\mathrm{a}}$ & $73.93^{\mathrm{ab}}$ & $73.85^{\mathrm{a}}$ & $74.52^{\mathrm{ab}}$ & 1.336 \\
\hline Feed intake, g/day & $135.4^{\mathrm{ab}}$ & $131.6^{\mathrm{b}}$ & $137.9^{\mathrm{a}}$ & $133.7^{\mathrm{ab}}$ & $134.3^{\mathrm{ab}}$ & $135.9^{\mathrm{ab}}$ & 1.659 \\
\hline $\begin{array}{c}\text { Feed conversion ratio, } \\
\text { g/100g egg mass }\end{array}$ & $2.75^{\mathrm{a}}$ & $2.50^{\mathrm{C}}$ & $2.64^{\mathrm{ab}}$ & $2.64^{\mathrm{ab}}$ & $2.59^{\mathrm{bc}}$ & $2.64^{\mathrm{ab}}$ & 0.041 \\
\hline \multicolumn{8}{|l|}{ Eggshell quality } \\
\hline Broken \& soft egg, \% & $1.57^{\mathrm{a}}$ & $1.42^{\mathrm{ab}}$ & $1.72^{\mathrm{a}}$ & $0.99^{\mathrm{ab}}$ & $0.94^{\mathrm{ab}}$ & $0.46^{\mathrm{b}}$ & 0.356 \\
\hline Eggshell strength, g/ $\mathrm{cm}^{2}$ & $3,670.60^{\mathrm{ab}}$ & $3,681.30^{\mathrm{ab}}$ & $3,616.50^{\mathrm{ab}}$ & $3,784.40^{\mathrm{ab}}$ & $3,608.50^{b}$ & $3,834.30^{\mathrm{a}}$ & 70.03 \\
\hline Eggshell color ${ }^{2)}$ & 9.56 & 9.67 & 10.07 & 10.06 & 9.57 & 9.89 & 0.237 \\
\hline \multicolumn{8}{|l|}{ Eggshell color ${ }^{3)}$, } \\
\hline Color tone & $14.13^{\mathrm{ab}}$ & $13.80^{\mathrm{b}}$ & $14.32^{\mathrm{a}}$ & $14.31^{\mathrm{a}}$ & $14.05^{\mathrm{ab}}$ & $14.42^{\mathrm{a}}$ & 0.157 \\
\hline Chromaticity & 17.54 & 17.55 & 17.69 & 17.64 & 17.63 & 17.33 & 0.127 \\
\hline Egg yolk color ${ }^{4}$ & $8.06^{\mathrm{e}}$ & $8.75^{\mathrm{d}}$ & $9.62^{\mathrm{C}}$ & $10.16^{\mathrm{b}}$ & $10.94^{\mathrm{a}}$ & $10.72^{\mathrm{a}}$ & 0.142 \\
\hline
\end{tabular}

1) T1; Control, T2; Control + $\beta$-carotene 25 ppm, T3; Control + Glutinicus $0.5 \%$ T4; Control + Glutinicus $1 \%$, T5; Control + Glutinicus $2 \%$, T6; Control + Glutinicus $4 \%$.

${ }^{2)}$ Determined by Eggshell Color Fan(Samyang Feed Co.).

${ }^{3)}$ Determined by Color Difference Meter.

4) Determined by Roche Color Fan.

${ }^{\mathrm{a}-\mathrm{e}}$ Means within each row with no common superscript $\operatorname{differ}(\mathrm{P}<0.05)$.

료 요구율(FCR)은 $\beta$-carotene 첨가구가 가장 낮 았으며 효모첨가구들이 대조구에 비해 낮았는 데, 유와 백(1990) 및 $\operatorname{Lim}(1992)$ 의 보고에서도 효모제제들이 사료 효율을 개선 시켰다. 그러 나 Brake(1991)의 경우 육계 종계사료에 생효모 배양물을 첨가했을 때 사료효율에 영향을 주지 않는다고 하였다.

2. 난각 색도 및 색상, 연파란 발생율, 난각 강도

Table 4에서 보는 바와 같이, Color Fan을 이 용한 난각 색 측정과 Color Difference Meter 를 이용한 난각 색도 측정에서 대조구와 모든 처리 구에서 유의적 차이가 없었으며, Color Difference Meter를 이용한 난각 색상(color tone)은 $\beta$-carotene 첨가구가 가장 낮았다. 연파란 발생율은 6주 평균에서 모든 처리구에서 대조구 보다 좋은 경향이 있었는데 특히 Glutinicus 첨가량이 높아
질수록 연파란율이 감소하는 경향을 보였다. 이와 같은 결과는 백색 레그혼 산란계에 효모 를 급여했을 때 연란을 적게 낳아 난질의 개선 이 증명되었다는 $\operatorname{Lim}(1992)$ 의 보고와 유사하였 다. 난각 강도는 Glutinicus $4 \%$ 첨가구가 가장 높았지만, 연파란 발생율과 반비례하지 않는 결과를 보여 이들의 상관관계에 대한 더 많은 연구가 요망된다.

\section{3. 난황 색도}

Table 4에서 보는 바와 같이, Color Fan을 이 용한 난황 색도 측정에서 매주 유의적 변화를 나타내었으며 6주 평균에서 Glutinicus를 첨가한 처리구들이 대조구 보다 높았으며 $\beta$-carotene 첨 가구보다도 더 높게 나타났다. 또한 Glutinicus 첨 가 수준이 높을수록 착색도가 높았지만 Glutinicus $2 \%$ 와 Glutinicus $4 \%$ 첨가구 간에는 유의적 차 이가 없었다. 
계란 난황의 착색도는 계란의 영양가치에 영 향을 미치는 요소는 아니지만, 일반적으로 소 비자는 짙은 황색의 것을 선호하고 있으며 또 한 소화기 장해나 내부 기생충에 감염된 닭은 섭취량 감소 또는 흡수저하가 발생하는 경우가 있으므로 계란 착색도는 닭의 건강상태를 나타 내는 것으로 간주되기도 한다(Herrick, 1971). 사료급여에 의한 난황색도의 변화는 급여 후 1 일부터 발생하나 안정된 색소를 위해서는 4 5 일 이상이 필요하며 체내에 누적된 색소물질이 완전히 고갈되는 데에도 10 일 이상의 기간이 필요하다(Hatzipanagiotou, 1984). 일반적으로 계 란의 황색 정도는 Roche color fan score로 표시 하며 가장 선호도가 높은 계란의 난황색은 Roche color fan score $11 \sim 12$ 이며 일반 계란의 난황은 6 7을 나타낸다(Roche, 1988). 이러한 계란의 난황착색은 기본적으로 난황 내에 노란 색 색소인 canthaxanthin과 붉은색 계열인 astaxanthin이 $3: 1$ 로 축적 될 때 더욱 선명한 오렌 지색의 score $11 \sim 12$ 를 나타내게 된다(Roche, 1988). 본 실험에서 대조구의 난황색도는 8.06으 로 비교적 양호하였으며 Glutinicus $2 \%$ 첨가구가 10.94 로 소비자의 선호도가 가장 높은 $11 \sim 12$ 에 근접하였다.

이상의 결과를 종합적으로 고찰해 보면, 산 란계 사료에 Glutinicus $0.5 \%$ 첨가 수준에서 생 산성 개선 효과가 가장 높았으며, 난황색도는 $2.0 \%$ 수준에서 가장 높았다.

$$
\text { IV 요 약 }
$$

본 연구는 사료 내 Rhodotorula glutinis(Glutinicus) 효모의 첨가가 계란의 생산성, 난각 및 난황 색도에 미치는 영향을 구명하고자 72주령 의 갈색 산란계 ISA Brown 360수를 공시하여 control, $\beta$-carotene 25ppm, $0.5 \%, 1 \%, 2 \%$ 그 리고 $4 \%$ Glutinicus로 처리하여 시험하였다. 각 각의 처리구는 3 반복, 반복당 20수씩, 한 케이 지당 2수씩 배치하여 6주간 사양시험을 실시하 였다.

Glutinicus 첨가구 중 $0.5 \%$ 수준 $(\mathrm{p}<0.05)$ 에서 사료요구율(FCR)과 계란 생산성 개선이 유의하
게 나타났으며 연파란 발생율은 Glutinicus 첨가 량 수준이 증가함에 따라서 감소하였다. 난각 강도는 Glutinicus $4 \%$ 첨가 시에 가장 높았으 며, 난황 색도는 Glutinicus가 증가함에 따라서 2 $\%$ 첨가까지 점차적으로 증가하였지만 Glutinicus $4 \%$ 첨가구와 $2 \%$ 첨가구와는 유의적으로 차이 가 없었다. 결론적으로 Glutinicus $0.5 \%$ 첨가가 계란 생산성을 증진시킬 수 있고, 난황 착색을 위해서는 Glutinicus 2\% 첨가가 효과적이었다. (색인 : Glutinicus, 계란 생산성, 연파란 발생율, 난황 색도)

$$
\mathrm{V} \text { 사 사 }
$$

본 실험은 2003년도 농림부 농림기술개발사 업의 현장 애로 과제((주)유진사이언스) 중 위 탁과제로 실시하였다. 시험 수행에 있어서 여 러가지로 협조해 주신 (주)유진사이언스의 최주 희 님과 김명국 님께 깊은 감사를 드리는 바 입니다.

\section{$\mathrm{VI}$ 인 용 문 헌}

1. AOAC. 1990. Official Method of Analysis. $15^{\text {th }}$ ed. Association of Official Analytical chemist. Washington, D. C.

2. Bauerfeiend, J. C. 1981. Carotenois as colorants and vitamin A precursors. Academic Press. New Yolk, p. 1.

3. Bindu, S., Somashekar, D. and Joesph, R. 1998. A comparative study on permeabilization treatments for in situ determination of phytase of Rhodotorula gracilis. Lett. Appl. Microbiol. 27:336-340.

4. Brake, J. 1991. Lack of effect of a live yeast on broiler breeder and progeny performance. Poultry Sci. 70:1037.

5. Cartwright, C. P., Juroszek, J. R., Beavan, M. T., Ruby, F. M. S., de Morais, S. M. F. and Rose, A. H. 1986. Ethanol dissipates the proton-motive force across the plasma menbrance saccharomyces cerevisias. J. General Microbial. 132:369.

6. Cole, D. S. A. and Haresign, W. 1989. Recent developments in Poultry nutrition. p. 145.

7. Dua, P. N., Day, E. J., Hill, J. E. and Grogan, C. O. 1967. Utilization of xanthophylls from natural sources by the chick. J. Agr. Food Chem. 15:324328. 
8. Esmail, S. H. M. 2003. Nutritional limits to poultry production from some conventional and unconventional feed stuffs. Poultry International Vol. 42, No. 9, pp. 43-45.

9. Eugiena, M., Talos, D., Panaitescu, M., Contrea, A., Trif, A., Caprita, R., Bogdan, G. H., Gravila, C., Manu, C., Driha, R., Coman, M. and Marinovici, A. V. 1997. Studies on metabolic role of Rhodotorula rubra 120r carotenoids pigments, used as a fodder additive concentrate, in laying hens nutrition. Roum. Biotechnol. Lett. 2:55-6015.

10. Gerendia, D. T., Gippert, H. I. F. and Fereucue, H. 1992. Addition of yea-sacc to diets new Hampshire parent stock. Biotechnology in the Feed Industry. Proc Alltechs $8^{\text {Th }}$ Annual Symp, Alltech Publ, Ky. p. 46.

11. Hatzipanagiotou, A. and Hartfiel, W. 1984. Deposition of a carotenoid into the egg yolk from the body stores by providing ration with fresh or strong oxidated soya oil. European Poultry Sci. 48:155.

12. Herrick, G. M. 1971. Repletion and depletion of pigmentation in broiler skin and shanks. Poultry Sci. 50:1467.

13. Kearsley, M. W. and Rodriguez, N. 1981. The stability and use of natural colours in foods: Anthocyanin, $\beta$-carotene and Riboflavin, J. Food. Technol. 16:421-431.

14. Lim, D. V. M. 1992. Effect of diet quality and Yea-Sacc 1026 on performance of commercial layer. Biotechnology in the Feed Industry. Alltech Pub., Ky. p. 412.

15. Marusich, W. L. and Bauernfeind, J. C. 1981. Oxycarotenoids in poultry feeds. pp. 319-462. in Carotenoids as Colorants and Vitamin A Precursors. J. C. Bauernfeind, ed. Academic Press, Inc., New York, NY.

16. Miki, W. 1991. Biological function and activities of carotenoids. Pure. Appl. Chem., 63:141.

17. Nelis, J. J. and DeLeenheer, A. P. 1991. Microbial sources of carotenoid pigments used in food and feeds. J. Appl. Bacteriol. 70:181-191.

18. Newbold, C. J., Williams, P. E. V., Mackin, N., Walker, A. and Wallance, R. J. 1990. Effects of yeast culture on yeast numbers and fermentation in the rumen of sheep. Proc. of Nutr. Soc.
19. Pagan, J. P. 1989. Calcium, bind gut function affect phosphorus need. Feedstuffs. August. 21.

20. Perrier, V., Dubreucq, E. and Galzy, P. 1995. Fatty acid and carotenoid composition of Rhodotorula strains. Arch, Macrobiol. 164:173-179.

21. Pierre, A. 1997. Food carotenoids and cancer prevention ; An overview of current research. Trends in Food Sci. Tech. 8:406.

22. Ringrose, R. C. 1949. Nutritive properties of torula yeast for poultry. Poultry Sci. 28:75-83.

23. Roche Com. 1988. Egg yolk pigmentation with carophyll, Brochure 1218.

24. Rose, A. H. 1987. Yeast, a microorganism for all species: a theoretical look at its mode of action. pp. 113-115.

25. SAS Institute, Inc., 1985. SAS Users Guide: Statistics. Version 6 Edition. SAS Institute Inc., Cary, NC.

26. Shin, H. T., Bae, H. D., Chung, K. W., Kim, Y. K., Shon, J. H. and Lee, S. K. 1990. Evaluation of live yeast culture as source of probiotics for broiler. $5^{\text {th }}$ AAAP:3:1.

27. Tee, E. S. 1992. Carotenoids and retinoids in human nutrition. Cri. Rev. Food Sci. Nutr., 31:103.

28. Twining, P. V., Bossard, E. H., Lund, P. G. and Thomas, O. P. 1971. Relative availability of xanthophylls from ingredients based on plasma levels and skin measurements. pp. 90-95 in : Proc. Md. Nutr. Conf.

29. 고용균, 황영환. 1999. Aspergillus Oryzae 균주로 배양한 효모 배양물의 급여가 브로일러의 육성 성적에 미치는 영향. 한축지 41(1):15-22.

30. 박평규, 김의용. 2002, Rhodotorula glutinis로부터 Carotenoids의 추출 방법. Korean J. biotechnol. Bioeng. 17:44-48.

31. 백인기. 1989. 생균제의 사용효과. 한영사보 13(3): 175-183.

32. 유종석, 백인기. 1990. 활성효모 첨가가 산란계의 생산성에 미치는 영향. 한국가금학회지. 17(3): 179-191.

33. 이을연, 이봉덕, 지설하, 박홍석. 1995. 생효모배 양물의 급여가 산란계의 생산성에 미치는 영향. 한국가금학회지 22(2):77-84.

34. 홍상필. 1996. 천연 carotenoid의 생물활성과 이용 전망. 식품기술. 9:406.

(접수일자 : 2004. 8. 30. / 채택일자 : 2004. 12. 13.) 